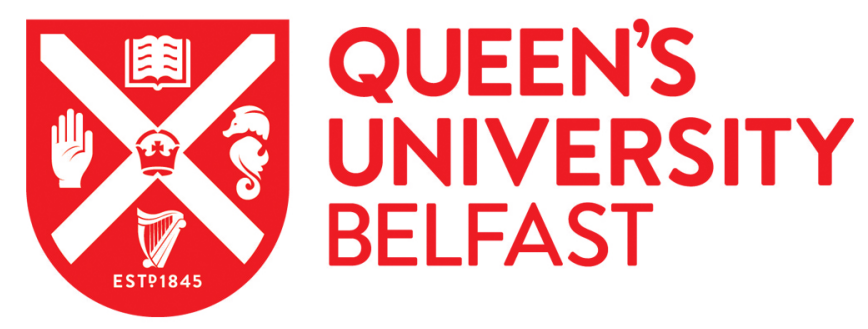

\title{
Lost in translation? The challenges of measuring informal care among children and young people
}

Kelly, G., Devine, P., \& McKnight, M. (2017). Lost in translation? The challenges of measuring informal care among children and young people. International Journal of Care and Caring, 1(3), 389-407.

https://doi.org/10.1332/239788217X15084960724368

\section{Published in:}

International Journal of Care and Caring

\section{Document Version:}

Peer reviewed version

Queen's University Belfast - Research Portal:

Link to publication record in Queen's University Belfast Research Portal

\section{Publisher rights}

Copyright 2017 Policy Press. This work is made available online in accordance with the publisher's policies. Please refer to any applicable terms of use of the publisher.

\section{General rights}

Copyright for the publications made accessible via the Queen's University Belfast Research Portal is retained by the author(s) and / or other copyright owners and it is a condition of accessing these publications that users recognise and abide by the legal requirements associated with these rights.

Take down policy

The Research Portal is Queen's institutional repository that provides access to Queen's research output. Every effort has been made to ensure that content in the Research Portal does not infringe any person's rights, or applicable UK laws. If you discover content in the Research Portal that you believe breaches copyright or violates any law, please contact openaccess@qub.ac.uk. 


\title{
Lost in translation? The challenges of measuring informal care among children and young people
}

\author{
Dr Grace Kelly, Queen's University Belfast \\ Dr Paula Devine, Queen's University Belfast \\ Dr Martina McKnight, Queen's University Belfast
}

\section{Introduction}

According to data in the UK Census of Population, the number of young carers aged between 5 and 17 years old increased substantially between 2001 and 2011. By 2011, 2.1\% of young people aged 5 to 17 years in England and Wales were young carers (ONS, 2013). The comparative figure for Scotland was $2 \%$ (NRS, 2011), while for Northern Ireland it was 2.8\% (NISRA, 2011). Prevalence estimates for young carers vary widely across different surveys, however, for several reasons. The first main issue relates to question wording, such as, 'is the question easy to understand?' and 'does the question use child-friendly language?'. Secondly, survey design and implementation is important, as different modes of administration (online, paper, face-to-face), as well as who completes the questionnaire, will impact on responses. It is also important to consider attitudes and norms among young people and their family members. Some young people may consider their activities and responsibilities to be 'caring', while others see them as a normal part of family life. In particular, these attitudes can be affected by a fear of intervention by the state if the child's or young person's caring role is identified. Nevertheless, despite these limitations, where standard questions and administration are used, surveys can successfully capture real variations, such as those between different age groups or in different regions.

One possible epistemological issue, and the subject of this paper, is that questions in different surveys are not all capturing the same thing. In other words, they reflect different conceptualisations of what it means to be a young carer. Thus, prevalence estimates across different surveys are often not comparing like with like. The aim of this paper is to explore the association between prevalence estimates and question wording. We do this by identifying survey instruments that provide prevalence estimates in the United Kingdom, and further afield, and comparing their definitions, question wording, and prevalence estimates. We then report on a small, qualitative, study in Northern Ireland, based on the Young Life and Times survey of 16 year olds, and the Kids' Life and Times survey of 1011 year olds, which focused on the difficulties involved in estimating young carer prevalence rates, and the wide variations in these rates arising from the method of data collection. The particular methodological challenges the study faced, and the approach taken to confront these complexities, are set out. The outcome is used to inform future plans for research in this area.

\section{Definitions of a 'young carer'}

Within the UK, definitions of who is a young carer have changed over the past 20 years, mostly as a consequence of specialist practitioner efforts to improve how young carers are identified, and in response to new legislation in England which imposes statutory duties on local authorities to provide support for young carers (Wayman et al, 2016). Definitions have latterly become more inclusive and specific, incorporating greater coverage of care, including emotional support, and making reference to the impact of the caring role on a young person's physical and mental wellbeing. As shown in Table 
1 , however, there remains a lack of consistency between definitions, and no consensus exists on when a young person's caring responsibilities become such that they characterise the role of a 'young carer'.

Table 1: Definitions of 'young carer' - UK

\begin{tabular}{|c|c|c|c|}
\hline $\begin{array}{c}\text { Study/ } \\
\text { Year }\end{array}$ & Introduction question & Age & $\begin{array}{l}\text { Prevalence } \\
\text { rate }\end{array}$ \\
\hline $\begin{array}{l}\text { UK } \\
\text { Census } \\
2001\end{array}$ & $\begin{array}{l}\text { Do you look after, or give help or support to family members, } \\
\text { friends, neighbours or others because of either: } \\
\text { - Long-term physical or mental ill health/disability? } \\
\text { - Problems related to old age? }\end{array}$ & $\begin{array}{l}5-17 \\
\text { years }\end{array}$ & $\begin{array}{l}2.5 \% \text { (N.I.) } \\
1.7 \% \\
\text { (E\&W) } \\
2.0 \% \\
\text { (Scotland) }\end{array}$ \\
\hline $\begin{array}{l}\text { LSYPE } \\
2004 \\
\text { (Hounsell } \\
, 2013 \text { ) } \\
\end{array}$ & $\begin{array}{l}\text { Some people your age may have to look after other people. This } \\
\text { could be a brother or sister, a relative or someone else who is } \\
\text { disabled or sick. Is there anyone like this who lives here with you } \\
\text { that you have to look after on a regular basis? }\end{array}$ & $\begin{array}{l}13- \\
14 \\
\text { years }\end{array}$ & $4.5 \%$ \\
\hline $\begin{array}{l}\text { Warren, } \\
2005\end{array}$ & $\begin{array}{l}\text { Do you look after or give special help to anyone at home who is } \\
\text { ill, has a disability or has other special needs? }\end{array}$ & $\begin{array}{l}9-18 \\
\text { years }\end{array}$ & $9 \%$ \\
\hline $\begin{array}{l}\text { Princess } \\
\text { Royal } \\
\text { Trust for } \\
\text { Carers, } \\
2004 \\
\end{array}$ & $\begin{array}{l}\text { This replicated Warren (2005) but it is not known if the exact } \\
\text { identification question was used as the study is unpublished. }\end{array}$ & $\begin{array}{l}7-19 \\
\text { years }\end{array}$ & $12 \%$ \\
\hline YLT 2007 & $\begin{array}{l}\text { Some people have extra family responsibilities because they } \\
\text { look after someone who is sick disabled or elderly. Is there } \\
\text { anyone living with you who is sick, disabled or elderly whom you } \\
\text { personally look after or give special help to? }\end{array}$ & $\begin{array}{l}16 \\
\text { years }\end{array}$ & $9 \%$ \\
\hline YLT 2010 & $\begin{array}{l}\text { A YOUNG CARER is a child or young person under } 18 \text { years of } \\
\text { age whose life is significantly affected by caring for a family } \\
\text { member who has an illness or disability or has a problematic use } \\
\text { of drugs or alcohol. CARING means carrying out everyday tasks } \\
\text { such as helping with washing or dressing, cooking and cleaning } \\
\text { as well as watching over someone so that they don't hurt } \\
\text { themselves. Caring can be just one or a combination of these } \\
\text { tasks. } \\
\text { Have you ever had caring responsibilities? }\end{array}$ & $\begin{array}{l}16 \\
\text { years }\end{array}$ & $10 \%$ \\
\hline BBC 2010 & $\begin{array}{l}\text { Unknown as no final report published. The study was carried } \\
\text { out using a special psychometric test - the Multidimensional } \\
\text { Assessment of Caring Activities for young carers (MACA YC18) } \\
\text { - devised by the University of Nottingham. }\end{array}$ & $\begin{array}{l}5-17 \\
\text { years }\end{array}$ & $8 \%$ \\
\hline KLT 2011 & $\begin{array}{l}\text { Some children your age have to help look after someone who is } \\
\text { sick, disabled or elderly. Is there anyone living with you who you } \\
\text { look after or give special help to? }\end{array}$ & $\begin{array}{l}10- \\
11 \\
\text { years }\end{array}$ & $12 \%$ \\
\hline $\begin{array}{l}\text { Census } \\
2011\end{array}$ & $\begin{array}{l}\text { Do you look after, or give help or support to family members, } \\
\text { friends, neighbours or others because of either: } \\
\text { - Long-term physical or mental ill health/disability? } \\
\text { - Problems related to old age? }\end{array}$ & $\begin{array}{l}5-17 \\
\text { years }\end{array}$ & $\begin{array}{l}3 \% \text { (N.I.) } \\
2.1 \% \\
(E \& W)\end{array}$ \\
\hline
\end{tabular}


This lack of consensus on definitions is evident in the examples which follow, drawn from guidance issued by senior professionals, usage in government-sponsored research and legislation in different parts of the UK.

In 2012, a joint Memorandum of Understanding between the (English) Association of Directors of Children's Services (ADCS), the Association of Directors of Adult Social Services (ADASS) and the Children's Society (a charity working to support vulnerable children in England and Wales) adopted the following definition:

The term young carer should be taken to include children and young people under 18 who provide regular or ongoing care and emotional support to a family member who is physically or mentally ill, disabled or misuses substances. ... A young carer becomes vulnerable when the level of care-giving and responsibility to the person in need of care becomes excessive or inappropriate for that child, risking impacting on his or her emotional or physical well-being or educational achievement and life chances.

(ADASS, ADCS, Children's Society, 2012: 7)

By contrast, a large programme of work commissioned by the UK's Department for Education on the lives of young carers in England in 2016 developed the following similar, but nevertheless significantly different, working definition of a young carer:

A young carer is a child / young person under the age of 18 who provides care in, or outside of, the family home for someone who is physically or mentally ill, disabled or misusing drugs or alcohol. The care provided by children may be long or short term and, when they (and their families) have unmet needs, caring may have an adverse impact on children's health, wellbeing and transitions into adulthood.

(Clay et al, 2016:18)

There is much overlap between these two definitions, but the second (Clay et al) takes into account care provided within or outside of the family home, whereas the 2012 Memorandum of Understanding focuses on the provision of support to a family member, without mentioning where that care takes place. The Memorandum of Understanding also makes reference to care being provided on a 'regular or ongoing' basis, and includes a reference to emotional support, whereas Clay et al's definition states that care may be 'long or short term', but makes no reference to emotional support.

Legislation relating to young carers in England is contained within the Care Act (2014) and the Children and Families Act (2014), which require local authorities to identify young carers and assess their support needs. The Care Act defines a young carer as: '... a person under 18 who provides, or intends to provide, care for an adult... A person is not a young carer if the person provides or intends to provide care under or by virtue of a contract, or as voluntary work' (see the Care Act, 2014: Section 63).

In Scotland, the Carers (Scotland) Act (2016), which builds on wider legislative frameworks, introduced new measures to improve the support given to young carers, intended to enable them to continue to care if they wish. There is, however, no definition of a young carer in this legislation, apart from the 
specification of the young carer's age and educational status (under 18 years old, or 18 years old and a pupil at school).

The equivalent legislation in Northern Ireland is the Children (NI) Order (1995). Here too, no fixed definition of a young carer is contained in the legislation. Young carers under 16 years of age may be assessed under the Children (NI) Order (1995), using a process called UNOCINI - Understanding the Needs of Children in Northern Ireland, and a young person aged 16 or 17 may also be assessed under the Children (NI) Order (1995). In Northern Ireland, a 16- or 17-year-old can also request an assessment under the Carers and Direct Payments Act (2002) (Carers NI, 2014).

In the UK, official statistics on the extent of care given by children and young people have (since 2001) been derived from the (ten yearly) Census of Population. Definitions of a 'young carer' can be derived from census data as the question on the provision of care is asked of all persons recorded on the census form, including children and young people (age data is also collected on all recorded persons). Carers under 18 years (aged 5 to 17) who provide unpaid care for family members, friends, neighbours or others because of long-term physical or mental ill-health, disability, or problems relating to old age, have been referred to as 'young carers' in most analyses using this data source (e.g. Becker and Becker, 2008; Dearden and Becker, 2004).

The Republic of Ireland's census only records information about provision of care on young people over the age of 15 years (Fives et al, 2013). Further afield, in Australia, researchers working with census data have defined a young carer as a young person up to the age of 25 years who provides unpaid care, help or assistance to family members or others because of a disability, a long term illness or problems relating to old age (Hill et al, 2009). This categorisation could also be made using the UK Census, since the concept of young carer is only applied after the data is collected. However, UK researchers and campaigners have mostly chosen to use the term 'young adult carer' for those aged 18-25, with the focus often being on the transition of 'child' to 'adult' (Becker and Becker, 2008; Becker and Sempik, 2013, 2014; Yeandle and Buckner, 2007). Research using census data in Canada (for 2001 and 2006) used the term 'young carer' for people aged up to 25 years providing unpaid care. The census in those years asked only about care provided to a child or a 'senior' (older person), thereby excluding other categories of care provision (Stamatopoulos, 2015). Canada's census no longer asks a question about caregiving although the General Social Survey (GSS) includes a module on 'Caregiving and Care Receiving'. However, the GSS is asked only of persons aged 15 years and older, so excludes young carers aged 14 or younger (Stamatopoulos, 2015: 820). In the USA, Hunt et al (2005) have defined a young carer as a young person aged between 8 and 18. These variations in official data collection and usage by researchers make international comparisons very difficult (see Table 2 ).

\section{Table 2: Definitions of 'young carer' - Australia, USA, Canada}

\begin{tabular}{|c|c|c|c|}
\hline $\begin{array}{l}\text { Study/ } \\
\text { Year }\end{array}$ & Introduction question & Age & $\begin{array}{l}\text { Prevalence } \\
\text { rate }\end{array}$ \\
\hline $\begin{array}{l}\text { Australia } \\
\text { Survey of } \\
\text { Disability, Aging } \\
\text { and Caring } \\
2003\end{array}$ & $\begin{array}{l}\text { 'a person of any age who provides an informal } \\
\text { assistance, in terms of help and supervision, to people } \\
\text { with disabilities or long-term conditions, or older people } \\
\text { (aged } 60 \text { years or over). This assistance has to be } \\
\text { ongoing, or likely to be ongoing, for at least six months'. }\end{array}$ & $\begin{array}{l}10-24 \\
\text { years }\end{array}$ & $7.6 \%$ \\
\hline USA & $\begin{array}{l}\text { Anyone aged } 8 \text { to } 18 \text { years who provides unpaid help or } \\
\text { care to any person who has an ongoing health problem }\end{array}$ & $\begin{array}{l}8-18 \\
\text { years }\end{array}$ & $\begin{array}{l}3.2 \% \text { of } \\
\text { household }\end{array}$ \\
\hline
\end{tabular}


Hunt et al. 2005 (using Omnibus data)

\section{Australia \\ Census \\ 2006}

Australia

Hill et al. 2009

(using 2006

Census data to

identify

'hidden' young

carers)

Canada

Stamatopoulos

2015

(using Census

2006 data) or chronic illness, or who is elderly, frail, disabled or mentally ill. In addition, to qualify as a caregiver, a parent had to report that the child helps the care receiver with one or more of the following tasks: household chores or meal preparation; dressing or feeding; taking medicine or talking to doctors and nurses; keeping him/her company, providing emotional support; shopping; paperwork, bills, or arranging outside services; moving around the house, getting around the community; bathing or using the bathroom' (Hunt et al., 2005:11).

In the last two weeks did the person spend time providing unpaid care, help or assistance to family members or others because of a disability, a long term illness or problems relating to old age?'

Potential carers are those young people aged 12-14 years who live with a person with a disability.

Potential carers (aged 15-24 years) are young people who live with a person with a disability but who did not identify as a carer.

Looking after one or more of this person's own children, or the children of others, without pay? Some examples include: bathing or playing with young children, driving children to sports activities or helping them with homework, talking with teens about their problems, etc., and;

Providing unpaid care or assistance to one or more seniors? Some examples include: providing personal care to a senior family member, visiting seniors, talking with them on the telephone, helping them with shopping, banking or with taking medication, etcetera. s include a

child

'caregiver'

aged

8 to 18

years

\section{5-24 $6.1 \%$}

years

$12-14 \quad 2 \%$

years

$15-24 \quad 3.5 \%$

years

$15-24$

$28 \%$

\section{Estimating the prevalence of young carers}

Estimating the number and experiences of young carers is important for policy and practice within the context of promoting the health and wellbeing of children and young people, particularly as providing care at a young age has been shown to impact negatively on a young person's physical and mental health (Aylward, 2009; Cree, 2003; ONS 2013; Waters and Rigby, 2008), educational achievement (Becker, 2007; Becker and Becker, 2008), training, employment and earnings (Audit Commission, 2010).

As with the issue of lack of consensus on definitions, there is also wide variation in estimates of the proportion of children and young people who are carers. Census of Population figures provide data based on the whole population, but the extent to which these reflect the true extent of caring by children and young people has been questioned by researchers whose quantitative surveys have reported much higher prevalence rates (e.g. Hunt et al, 2005; Warren, 2005; Devine and Lloyd, 2008, 2011; Hill et al, 2009; Lloyd, 2013). Several explanations have been put forward to explain the discrepancy between these findings and other estimates of scale. Wayman et al (2016) note, for 
example, that responsibility for completing the census return rests with the householder, and that a census return provides no indication of whether the young person answered the question themselves, or if it was completed by an adult on their behalf. Others have reported that young people and / or their families may not wish to disclose the extent of a young carer's role, for reasons which may include the fear of stigma, or of an institutional intervention that might lead to the break-up of the family (Frank, 1995; Dearden and Becker, 1997; Fives et al. 2013; Clay et al, 2016). Others claim families may not recognise their own children as carers (Smyth et al, 2011). These issues point to the likely existence of a substantial 'hidden' group of young carers (Becker, 2007; Hill et al, 2009), and figures derived from census data are considered, by some observers, to underestimate the true extent of caring among children (Warren, 2007, 2008; Lloyd, 2013).

Survey-based studies, such as those referred to above, are consistent with the results of qualitative studies with young carers, which have shown that children who report providing care are more likely to experience bullying and to be less happy in school (Becker and Becker, 2008), have poorer educational outcomes (Becker, 2007; Aldridge, 2008) and have limited opportunities to engage in social activities (Clay et al, 2016). These studies have captured an important facet of young care-giving in spheres of children's lives which may explain their absence from census data.

Much research on young carers has used qualitative designs, and been undertaken with groups of young people identified through carer projects (Lloyd, 2013). These studies provide valuable information on what it is like to be a young carer. Other studies have used mixed methods approaches. For example, Becker and Becker (2008) analysed UK Census of Population data, but also used in-depth interviews and focus groups, and carried out a survey of young carers in Britain. Based on a review of the literature, stakeholder consultations and analysis of nationally representative datasets in Australia, Hill et al (2009) identified a 'potential' pool of 'hidden young carers', estimating the number of young people aged 12-14 who live with a person with a disability, and the number of young people aged 15-24 years who live with someone with a disability but do not identify themselves, in the survey, as a carer. In the UK, the Children's Society (Wayman et al, 2016) investigated the increase in the number of young carers between 2001 and 2011 using Census of Population data, reviewed the literature on prevalence rates and undertook new qualitative work, including interviews with young carers and a small number of parents and young carer project workers. Work commissioned by the Department of Education (Cheesbrough et al, 2017) investigated the characteristics and circumstances of young carers aged 5 to 17 years in England. Although this included a feasibility study to identify a suitable, cost-effective, quantitative approach to estimate the prevalence of young caring, and a survey of parents of young carers (and, where possible, of young carers themselves), the researchers did not consider it appropriate to generate a prevalence rate based on the quota sampling methodology used (Cheesbrough et al, 2017: 12).

Although few large-scale random sample surveys of children and young people have measured the prevalence and correlates of caring at a young age, in the decade between the two UK Censuses of Population (2001 and 2011), some UK studies produced survey estimates. For example, Warren (2005) randomly selected 378 young people aged 9 to 18 in 'public areas' (e.g. youth clubs, a shopping centre, near schools), among whom 34 (9\%) identified themselves as looking after, or giving special help to, someone at home who was ill, had a disability or other special needs. This study was subsequently replicated by the Princess Royal Trust for Carers (in an unpublished study) which had a representative sample of over 1,300 children and young people aged 7 to 19 , among whom $12 \%$ reported carrying out caring tasks (PRTC, 2004).

In 2007, the Young Life and Times survey in Northern Ireland asked its 627 participants (all aged 16 years old) if they had extra family responsibilities because they looked after someone who lived with 
them who was sick, disabled or elderly. Just under one in ten of these young people (9\%) said that they did (Devine and Lloyd, 2008). More detailed questions on the level and type of care provided by young people were included in the 2010 Young Life and Times Survey, also in Northern Ireland; among the 786 young people who took part in that survey, $10 \%$ indicated that they provided care for someone (Devine and Lloyd, 2011).

A study carried out by the University of Nottingham for the BBC (British Broadcasting Corporation) estimated that, across the UK, the number of children acting as carers for members of their families was more than four times the official census estimate. This used a survey of over 4,000 secondary school aged pupils, and showed that a 'hidden army' of around $8 \%$ of the young people who took part had 'moderate or high levels' of caring responsibilities, defined as 'caring intimately for a close relative, including helping them bathe, dress or go to the toilet' (BBC, 2010). By contrast, Hounsell (2013), using data from the Longitudinal Survey of Young People in England (LSYPE)', reported that, of the young people who took part in the first wave of this survey, only $4.5 \%$ identified themselves as having caring responsibilities.

While the findings from these surveys are consistent with the results of qualitative studies with young carers, and show that children who report providing care are more likely to experience poorer health, educational and social outcomes, there is wide variance in the estimates of the prevalence of young caring derived from surveys (most of which have focused on older children) and census data. This has resulted in conflicting views about whether data in the UK Census of Population underestimate the true picture of young carers, or survey-based estimates exaggerate the situation.

We turn now to consideration of two surveys conducted in Northern Ireland which shed some light on this issue.

Surveys of young carers in Northern Ireland.

The 2011 Kids Life and Times survey investigated the happiness and well-being of 4,192 'Primary 7' children (aged 10 to 11 years) in Northern Ireland. Participating children answered a range of questions about aspects of their lives, including whether they had caring responsibilities and the nature of these tasks (Lloyd, 2013). Approximately one in eight participants (12\%) said they looked after, or gave special help to, someone who was living with them.

One of the advantages of this survey was the additional data provided by the inclusion of an openended question asking those who self-identified as a young carer, 'What kind of things do you help them with?' This provided information on the type of tasks carried out, with responses indicating that many children were carrying out a range of personal tasks for people living with them, over and above those which would be expected from a child of their age. Some responses also indicated that young children may have interpreted the caring question in a broader sense, however, as several responses referred to everyday tasks such as washing dishes and helping younger siblings with homework. Responding to this, and prior to the inclusion of a module on caring in the Kids Life and Times and Young Life and Times surveys conducted in 2015, young carers were consulted on how to make the distinction between caring and non-caring roles clearer. The young people's recommendations informed the final questions used in the surveys, including re-wording of the introduction question. The remainder of this article examines the outcome of the 2015 surveys, and considers the extent to which these recommendations about question wording helped children and young people to recognise the tasks and responsibilities that would constitute the role of a young carer. 


\section{Method}

The 'Young Life and Times' and 'Kids Life and Times' surveys are annual, cross-sectional, surveys of 16 year olds and 10 to 11 year olds respectively. Both surveys are run by Access Research Knowledge (ARK, a joint initiative between the two universities in Northern Ireland) and are widely used by government and voluntary sector organisations to monitor policy and young people's attitudes on a wide range of issues.

The Young Life and Times survey records the views of 16 year olds in Northern Ireland on a range of issues. Each year, respondents are invited to suggest topics for the next year's survey as a way of ensuring these remain relevant and fresh to 16 year olds. The Young Life and Times sample is taken from the Child Benefit Register provided by Her Majesty's Revenue and Customs (HMRC), the government agency which administers Child Benefit (a state benefit payable throughout the UK, for which most parents of dependent children are eligible). Young Life and Times is a postal survey, with options to complete the questionnaire online or by phone if respondents do not, or cannot, complete the paper questionnaire. Approximately 4,000 16 year olds are eligible for inclusion in the sampling frame, from which approximately $30-40 \%$ agree to participate.

Kids Life and Times is an annual online survey of 10- to 11-year-old children in their final year at primary school. The purpose of the survey is to give children a voice in policy-relevant issues that affect their lives, such as education, health and wellbeing. As with Young Life and Times, participants in the Kids Life and Times survey are asked to suggest topics for inclusion in the following year's survey to ensure the surveys cover issues that are important to children. The data required to access the target population is provided by the Department of Education (DE) which has overall administration of the education system in Northern Ireland.

The young carer prevalence rates derived from the questions on caring included in the Young Life and Times surveys in 2007, 2010 and in the Kids Life and Times survey in 2011 were 9\%, 10\% and 12\% respectively. Consistent with most survey findings, these estimates were significantly higher than those recorded in the 2011 Census of Population (Table 1).

As recommended by Lloyd (2013), and in line with the view that children's participation should be optimised in issues that affect them (Hill, 2006), the ARK team involved young carers in the questionnaire and study design for the 2015 caring module. Contact was made with an organisation that runs a young carers' group, made up of children and young people aged 8 to 17 years. The organisation was advised of the aims of the research, and permission was requested to speak with a group of young carers to ask for their advice and input. The young people were happy to help, and a consultation meeting was held with 15 young people ( 7 male, 8 female) aged 13-17 years, plus a member of the ARK team. Two members of staff from the organisation, well known to the group, helped facilitate the discussion, in which participation was voluntary. The discussion was not recorded, but comprehensive notes were taken by a researcher.

An overview of the ARK surveys was given, and the young people were asked their opinions on the relevance of the questions for a young carer, with each given a copy of the detailed caring questions included in the 2010 Young Life and Times survey, and asked to make notes on what they felt did, or did not, work. They were asked to focus on the introduction question (Table 1) and to make suggestions about how the wording of this might help a young carer recognise themselves as such. The young people suggested various changes they felt better represent the life of a young carer, aiding clearer interpretation of the concept. 
The introduction to the 2010 Young Life and Times questions stated that the life of a young carer was 'significantly affected by caring for a family member who had an illness or disability or a problematic use of drugs or alcohol', and some examples of caring tasks were given. The young people disliked the term 'significantly affected', as they viewed caring as part of their everyday life, even though they knew their lives were different to those of many of their friends. They also felt that while care was nearly always given to a family member, this was not necessarily the case. They felt that the examples of caring tasks should include emotional support and reassurance, pointing out that most young people and children help out around the home, doing cleaning or helping with shopping and such like, but that being a young carer was more than 'helping out': it was providing 'ongoing care and support', and it was important that this distinction was understood.

In relation to follow-on questions using the word 'disabled', the young carers felt a distinction should be made between physical disabilities and learning difficulties, and that questions about caring tasks, or who one cared for, should include mental and emotional problems. Many of the young people found it difficult to define specific hourly blocks of time spent caring per week, seeing caring as part of everyday life, or, in some cases, were caring for someone whose condition fluctuated between 'good' and 'bad' days.

The suggestions the young people made were used to finalise the questions included in the 2015 Kids Life and Times and Young Life and Times surveys (available online at: http://www.ark.ac.uk/ylt/2015/YLTquest2015.pdf and http://www.ark.ac.uk/klt/2015/quest15.pdf) and to reword the introduction to the caring questions (see Box 1 ).

\section{Box 1}

\section{Young Life and Times 2015 - Main introduction question}

'Most young people help out at home with, for example, shopping or cleaning. However, some also provide ongoing care and support to someone who is elderly, has a long term illness or a disability. Sometimes called 'Young Carers', they help with everyday tasks, such as helping someone to get washed and dressed, providing someone with emotional support and reassurance, or watching over them so that they stay safe.

Thinking about what we have said above, do you give any special help or extra care to someone?'

\section{Kids Life and Times 2015 - Main introduction question}

'Lots of children help out at home with shopping or cleaning. But as well as helping out like this, some children your age give extra care or support to someone, usually someone in their family, who is elderly (old), or has a long term illness or disability.

Do you give any special help or extra care to someone?' 


\section{Fieldwork}

Fieldwork for the 2015 Young Life and Times survey was undertaken between October and December 2015. An initial information sheet on the study was posted to the home addresses of the target sample for the study, and recipients were given an opportunity to opt out at this stage. Two weeks later, those not opting out received further information and the paper questionnaire for completion. A link to an online version of the survey was also forwarded in case young people preferred to complete the survey online; and a telephone number was provided should they wish to complete the questionnaire by phone.

Fieldwork for the 2015 Kids Life and Times survey was undertaken from November 2015 to January 2016. Letters were sent out to all primary schools in October 2015, giving information about the survey and when fieldwork would begin. Each school was allocated a unique identification number. Consent to participate in Kids Life and Times involved three stages:

- First, the school principal agreed that the school could participate.

- Second, a parent or guardian of each P7 pupil within the participating schools received a consent form to complete and return to the school if they did not wish their child to take part.

- Third, at the start of the questionnaire, each child was asked if $s /$ he agreed to take part.

A total of 1,158 16-year-olds responded to the 2015 Young Life and Times survey. For Kids Life and Times, the total number that took part was 5,194. Both surveys included a module on caring responsibilities, with the introduction and question wording revised to reflect the recommendations made by the young carers. Children and young people who said they gave special help or extra care to someone were asked to answer who that person was, why they needed the extra help, what kind of things they did to help and whether or not giving help affected them in different domains of their life. The Young Life and Times and Kids Life and Times respondents were given the opportunity to expand on their experience of caring by responding to a number of open-ended questions.

\section{Ethics}

Ethical approval to carry out the Young Life and Times and Kids' Life and Times surveys was obtained from the Ethics Committee located in the School of Social Sciences, Education and Social Work at Queen's University Belfast. Permission to access the addresses of recipients of Child Benefit for the Young Life and Times survey was granted to ARK after a statutory instrument and explanatory memorandum was approved by Parliament in Westminster in 2004. Data security and confidentiality are subject to a Memorandum of Understanding and a Service Level Agreement with HMRC. Approval to visit and speak with a group of young carers was granted from the carers organisation Lead, following consultation with the young people themselves.

\section{Data analysis}

All analyses were conducted using SPSS Version 21. Chi-squared tests were used to assess the association between the caring variable and health, bullying and school and family affluence (measured using the Family Affluence Scale). 


\section{Results}

\section{Young Life and Times}

Results for 2015 Young Life and Times were similar to those obtained in 2007 and 2010, with almost one in ten (9\%) 16-year-olds saying they gave special help to someone. Slightly more females said they looked after someone (10\%) compared with males $(8 \%)$, although the difference was not statistically significant. Most of these young people said they looked after one person (76\%); the rest looked after two or more people.

The person most likely to be cared for was a grandparent $-42 \%$ said they were caring for a grandmother or grandfather; this was followed by a sibling (32\%) and their mother (28\%). Smaller percentages of respondents cared for their father $(10 \%)$ or 'someone else' $(10 \%)$. The majority of young people provided care that was mostly split between physical / practical and emotional care. A small percentage (11\%) described the type of care they provided as 'other'. Respondents who ticked the 'other' category were given the opportunity to specify the task / activities further. For the small number of respondents who chose this category, and expanded on their answer, their notion of 'young carer' was broader than the researchers had anticipated would be captured under this refined definition. Comments included such things as, 'protecting and looking after brothers and sisters' and 'taking the dog for a walk' as among the 'other' tasks carried out.

However, those who chose to say more about their experiences of caring (by responding to the question 'Is there anything else you would like to say about being a Young Carer?'), gave accounts closer to the conceptual understanding of caring anticipated by the researchers; that is, carrying out tasks, or having responsibilities, over and above those of their peers:

Being a young carer can be quite hard at times, but I will always love my brother no matter what. It can be stressful and get in the way of my school work, but that's just life. You have to pick yourself up and get on with it.

Nevertheless, among those who did self-identify as a young carer, and who went on to expand on their experiences, there was an element of uncertainty in a small number of statements as to whether or not they thought they were a carer:

I don't really know if I am a young carer. I mostly just try to support my dad when he is depressed / suicidal. A lot of the responsibilities I take on could be seen as normal chores.

The responsibilities described in the above quote evidently fit within the definition of a young carer, yet there was some hesitation displayed by the young person about identifying as a carer. It had been anticipated that the consultation with the young carers' group would have minimised any ambiguity between tasks which would constitute young caring. Eliminating all uncertainty may be unrealistic, however, particularly as previous research has shown 'hidden' young caring to be a long-standing challenge that has proved difficult to overcome (Thomas et al, 2003; Barnardo's, 2006; Smyth et al, 2011). In this instance, the Young Life and Times' refined introduction question was successful in helping the respondent identify as a young carer. Furthermore, young people who identified as carers were more likely to report having an illness or disability $(16 \%)$ compared to their peers who were not providing care (11\%). This is consistent with a strong body of evidence which identifies the negative health implications for young carers (e.g. Becker and Becker, 2008; ONS, 2013; Clay et al, 2016; Wayman et al, 2016).

\section{Kids Life and Times}


Results for the 2015 Kids Life and Times survey showed substantially more children reporting that they provided care to someone (45\%) compared to the same survey in 2011 (12\%). This was much higher than expected, given the consultation work and revised questions. Three open-ended questions allowed children to expand further on their 'other' responses to the 'who, why and what' caring questions. Investigation of these open-ended responses indicated that, while some children did appear to be providing a level of care that could be conceived as untypical for someone their age, a number of children had interpreted the meaning of caring in a much broader way than the researchers had anticipated, associating 'special help' and 'extra care' with those they loved and cared about, rather than cared for, such as close family and friends. When asked 'who else do you give help to?', mother and father, brothers, sisters, grandparents, aunts, uncles, cousins and friends in school featured largely. Pets were also mentioned, although not as frequently. The following responses are indicative of who was being cared for:

All my family and friends.

Everyone in my family. I also pray for my family members who have passed away.

A child in my class and my brother.

Explanations as to why the person needed help corresponded, to a large extent, with reports of who was being cared for. For instance, caring because 'I look after the people I look after because I love them' and 'to be kind', 'to be nice' and 'just to be helpful' were common reasons. The type of tasks being carried out corresponded with responses to the 'who' and 'why' questions, where examples given included helping with household chores (like doing the dishes or tidying up), looking after younger siblings, and helping friends with homework. The connection that young people made between caring and loving those close to them was evident in expressions such as:

Give my grandparents lots of love.

Help with the housework, keep company and love.

Play games with them and make them feel loved.

At the same time, among the responses to the 'other kinds of things you do to help them', there were instances of children providing more demanding levels of care such as:

Cooking meals for him.

Help my sister with depression.

Help them down the stairs, get into cars and help them cook.

Helping when bloods are low.

When examining responses to the 'what and why' questions about providing extra care or support, there were enough references to serious medical conditions, like cancer, heart defects, kidney disease, chronic degenerative neuro-immune diseases, autism, Alzheimer's and numerous bone fractures, to suggest that a sizeable number of children lived in families where at least one family member required substantial levels of care.

Drawing somewhat on the work of Hill et al (2009), where 'potential' young carers were identified by estimating the number of children living with someone with a need for assistance, and the likelihood that young people will be providing some of that assistance, we focused on children giving care to someone they lived with. One in five $(20 \%)$ children were giving special help to at least one person in 
their household. Examination of this group's responses to the who question typically included references to immediate and close family members, mostly younger siblings, mother, father and grandparents, although a small number of references to friends remained. Responses by this group to the why question also contained references to helping because they love their family, but a larger proportion of responses cited, or alluded to, medical conditions or general sickness, like the following two children's reasons for giving extra care:

Because I love them, and if they're feeling sick.

My brother can get really confused and angry, so he needs me to be patient and calm.

These responses indicate how the boundaries between 'caring about' and 'caring for' can become quite blurred. Fisher and Tronto (1990) describe caring as a process that involves four interrelated aspects of care - 'caring about', 'taking care of', 'caregiving' and 'care receiving'. 'Caring about' involves being aware that care is needed, but does not necessarily mean that care will be provided. The next step (taking care of) involves taking responsibility for meeting the identified need. 'Caregiving', according to Fisher and Tronto's modes of care, involves carrying out caring activities which require taking on more obligations and responsibilities. Responses to the 'who, why and what' questions reveal a range within, as well as between, these modes of care. This is demonstrated by the following two children who both recognise that care is needed, but display differing levels of intensity of understanding:

Mummy needs more help around the house because she has four kids me and my three brothers.

She has asburgers [Asperger's Syndrome], plus she's my wee princess, I couldn't live with myself if anything happened to her.

The characteristics of the $20 \%$ of children who identified as a carer and were living with the people they gave care to, were similar to those of the young carers identified in the Kids Life and Times survey 2011. The people most likely to be cared for were grandparents (47\%) and siblings (41\%). Boys and girls were equally likely to be providing care. This group of children were significantly more likely than their peers who did not care for someone at home to say that they had been bullied physically, and experienced bullying in other ways, at school in the two months prior to the survey. Almost a third (29\%) of young carers had experienced a physical form of bullying, and $37 \%$ had been bullied in other ways, such as being called names and getting left out of games. The children providing care to someone at home were also significantly more likely to have been bullied online, compared with their peers (15\% compared to $11 \%)$. There were no significant physical health differences between young people providing care and their peers. However, there were important differences in socio-economic circumstances. Significantly higher proportions of P7 children from low affluence backgrounds said they provided extra care to someone they lived with $(28 \%)$, compared with children from medium affluence families (19\%) and high affluence families (16\%).

These results support existing research regarding the greater risks among young carers of experiencing bullying (Cheesbrough et al, 2017), explaining why some young carers prefer to hide their caring role in school (for fear of bullying). Economic disadvantage is another finding that corresponds with previous research suggesting that, for many, caring is related to financial vulnerability and low income (Hill et al, 2009; Hounsell, 2013).

\section{Discussion and conclusion}


Broadly, there have been two types of prevalence studies - those at census level and those using survey data. Census level prevalence estimates tend to coalesce around 2 to $5 \%$, while survey data estimates have tended to produce higher prevalence rates of around 9 to $15 \%$. This paper explored the association between prevalence estimates and definitions and question wording used to provide these assessments. Definitions vary by age range, relationship to care recipient, residence, duration of care provision, characteristics of care recipient and even the impacts of care provision. Consequently, variations in recorded prevalence rates reflect different conceptualisations of what it means to be a young carer. On the basis of this research, we believe an important first step would be to obtain consistency across census/national level prevalence studies, bearing in mind that the prevalence of young caring (as generally understood) is under-reported in census data. Thus, a reconsideration of question wording within the census would be useful.

Questions about the extent and nature of caring in the Young Life and Times survey in 2010 and the Kids Life and Times survey in 2011 identified high percentages of children and adolescents providing care. Analysis of the 2011 Kids Life and Times open-ended responses indicated that respondents' understanding of what constituted 'caring' was broader than that of the researchers. Yet, equally, the children who reported undertaking a caring role in the 2011 Kids Life and Times survey had poorer self-reported health, well-being and happiness with life overall than other children. They also experienced more bullying, were less happy in school, and tended to have poorer educational outcomes than children who were not carers (Lloyd, 2013). In an effort to differentiate between everyday caring tasks and the more substantial responsibilities associated with providing care, the ARK team consulted with young carers regarding the Young Life and Times and Kids Life and Times 2015 survey design and question wording.

Results for 16 year olds were similar to the Young Life and Times 2010 survey and remained consistent with the wider literature on caring, revealing the greater propensity for young carers to experience ill health. For 10-11 year old children, a larger than expected number identified themselves as providing extra care to someone. Analysis of the open-ended questions by younger children showed they were inclined to associate the concept of care with loving their family, being nice to their friends, their teacher and helping peers with their school work if they were having difficulty.

One of the main differences between the definition used in the Kids Life and Times surveys in 2011 and 2015 was that the 2011 definition asked if there was 'anyone living with you' to whom you give special help. The 2015 definition did not ask if the child lived with the person they helped. With this in mind, and drawing on wider literature, a prevalence rate was calculated based on children identifying as a young carer and living with the person they cared for. One fifth (20\%) of children were captured using this criterion. Based on a reading of the open-ended responses, this group includes children who could be described as providing 'light touch' caring tasks, such as helping with siblings. But given the complex, multi-dimensional nature of care, it is difficult to draw a line between 'caring about' and 'caring for'. Therefore, capturing those with reasonably light caring responsibilities is important. However, the extent to which these children may or may not be 'vulnerable' cannot be accurately determined.

Research has shown that a variety of circumstances can affect how young people experience their life as a carer. Influencing factors include the nature of the condition of the person being cared for and whether or not they have good support from other family members or social services (Cassidy et al, 2014). Clay et al (2016) describe the coping strategies that many young people adopt, to help them reduce stress associated with caring responsibilities and to better organise their lives around their commitments. Strategies included: keeping a diary, getting involved in outside activities and interests, and spending leisure time with parents and family members. It is possible that the young carers 
involved in the consultation had become so used to coping, that even if they acknowledged their lives were different to those of their friends, they might not view their situation as exceptional.

It is believed that the prior consultation undertaken would have benefited from having a combination of both carers and non-carers present. That way, the non-carers may have served as a check on the level of caring being discussed, and a more balanced view of what does, and does not, represent caring may have emerged. There is growing awareness that developing a methodology for capturing the number of young carers in the population should include consulting with a broader range of young people (Wayman et al, 2016; Cheesbrough et al, 2017). The research reported here fully endorses that advice, and the authors would further emphasise the need to consult broadly with young carers and their non-caring peers at the preliminary, developmental stages, in addition to the piloting and cognitive testing stages. There is also an emerging view that research can benefit from 'co-reflexive practice', where researchers and children and young people can reflect critically on the assumptions and beliefs each bring to the research (Moore et al, 2016: 242). For example, given the issue of lighter touch caring intimated in some of the open-ended responses, and the interconnection between modes of caring (Fisher and Tronto, 1990), the notion of 'young carer' that the researchers had in mind may have been too prescriptive. Making space for reflexivity is a course of action that the Kids Life and Times and Young Life and Times surveys have planned for the future.

\section{References}

ADASS, ADCS and The Children's Society (2012) 'Working together to support young carers and their families', cited in Hounsell, D. (2013) Hidden from View: the experiences of young carers in England, London: The Children's Society, p 6.

Aldridge, J. (2006) 'The experiences of children living with and caring for parents with mental illness', Child Abuse Review, 15(2), 79-88.

Audit Commission (2010) Against the odds: Targeted briefing - young carer, London: Audit Commission.

Aylward, N. (2009) Access to education and training for young adult carers, Policy Briefing Paper, National Institute of Adult Continuing Education and Nuffield Foundation.

Barnardo's UK (2006) Hidden Lives: Unidentified Young Carers in the UK, Essex: Barnardo's.

BBC (2010) "Hidden Army" of young carers could be four times as high as official figures, http://www.bbc.co.uk/pressoffice/pressreleases/stories/2010/11_november/16/carers.shtml

Becker, F. and Becker, S. (2008) Young adult carers in the UK: Experiences, needs and services for carers aged 16-24, London: The Princess Royal Trust for Carers.

Becker, S. (2007) 'Global perspectives on children's unpaid caregiving in the family: Research and policy on 'young carers' in the UK, Australia, the USA and Sub-Saharan Africa', Global Social Policy, 7, 23-48.

Becker, S. \& Sempik, J. (2013) Young Adult Carers at School: Experiences and Perceptions of Caregiving and Education, London: The Carers Trust.

Becker, S. \& Sempik, J. (2014) Young Adult Carers at College and University. The Carers Trust: London. The Care Act (2014) http://www.legislation.gov.uk/ukpga/2014/23/contents/enacted/data.htm

Carers NI (2014) Assessments: your guide to getting help, Factsheet NI1020, https://www.carersuk.org/images/Factsheets/Factsheet_NI1020_Assessments_-

_guide_to_getting_help.pdf 
Cassidy, T., Giles, M. and McLaughlin, M. (2014) 'Benefit finding and resilience in child caregivers', British Journal of Health Psychology, 19(3): 606-18.

Cheesbrough, S., Harding, C., Webster, H. and Taylor, L. with Aldridge, J. (2017) The lives of young carers in England, Omnibus survey report, Kantar Public, Loughborough University, London: Department of Health, https://www.gov.uk/government/publications/the-lives-of-young-carers-inengland

Clay, D., Connors, D. Day, N., Gkiza, M. with Aldridge, J. (2016) The lives of young carers in England, Department for Education and Loughborough University, https://www.gov.uk/government/publications/the-lives-of-young-carers-in-england

Cree, V.E. (2003) 'Worries and problems of young carers: Issues for mental health', Child \& Family Social Work, 8(4): 301-9.

Dearden, C. and Becker, S. (1997) Children in care, children who care: Parental illness and disability and the child care system, Young Carers Research Group, Gulbenkian Foundation, April 1997.

Dearden, C. and Becker, S. (2004) Young Carers in the UK, London: Carers UK.

Department of Education (2016) The lives of young carers in England, https://www.gov.uk/government/publications/the-lives-of-young-carers-in-england

Devine, P. and Lloyd, K. (2008) Young carers, ARK Research Update 56, http://www.ark.ac.uk/publications/updates/update56.pdf

Devine, P. and Lloyd, K. (2011) Young carers too, ARK Research Update 76 http://www.ark.ac.uk/publications/updates/update76.pdf

Fisher, B. and Tronto, J. (1990) 'Toward a feminist theory of caring', in E. K. Abel and M. K. Nelson (eds), Circles of care: Work and identity in women's lives, New York: State University of New York, pp 35-62.

Fives, A., Kennan, D., Canavan, J. and Brady, B. (2013) 'Why we still need the term 'young carer': Findings from an exploratory study of young carers in Ireland', Critical Social Work, 14(1): 49-61.

Frank, J. (1995) Couldn't care more: A study of young carers and their needs, London: The Children's Society.

Hill, M. (2006) 'Children's voices on ways of having a voice: Children's and young people's perspectives on methods used in research and consultation', Childhood, 13(1): 69-89.

Hill, T., Smyth, C., Thomson, C. and Cass, B. (2009) Young carers: Their characteristics and geographical distribution, Report to the National Youth Affairs Research Scheme, Sydney, Australia: Social Policy Research Centre, University of New South Wales.

Hounsell, D. (2013) Hidden from view: the experiences of young carers in England, London: The Children's Society.

Hunt, G., C. Levine and Naiditch, L. (2005) Young Caregivers in the US: Findings from a National Survey, National Alliance for Caregiving and the United Hospital Fund: Bethesda, Maryland.

Lloyd, K. (2013) Happiness and well-being of young carers: Extent, nature and correlates of caring among 10 and 11 year old school children, Journal of Happiness Studies, 14: 67-80.

Moore, T., Noble-Carr, D. and McArthur, M. (2016) 'Changing things for the better: the use of children and young people's reference groups in social research', International Journal of Social Research Methodology, 19(2): 241-56.

National Records of Scotland (2011) Scotland Census Results, http://www.scotlandscensus.gov.uk/census-results 
Northern Ireland Statistics and Research Agency (2011) Northern Ireland Census Results, NISRA Table DC3304NI, https://www.nisra.gov.uk/statistics/census/2011-census

Office for National Statistics (2013) Full story: The gender gap in unpaid care provision: is there an impact on health and economic position? http://webarchive.nationalarchives.gov.uk/20160105160709/http://www.ons.gov.uk/ons/dcp17177 6_310295.pdf

Princess Royal Trust for Carers (PRTC) (2004) Shocking New Figures on Number of Kids Caring, Press Release, 1 September 2004, London: Princess Royal Trust for Carers.

Smyth, C. Blaxland, M. and Cass, B. (2011) 'So that's how I found out I was a young carer and that I actually had been a carer most of my life', Journal of Youth Studies, Vol 14(2): 145-60.

Stamatopoulos, V. (2015) 'One million and counting: the hidden army of young carers in Canada', Journal of Youth Studies, 18(6), 809-22.

Thomas, N., Stainton, T., Jackson, S., Cheung, W., Doubtfire, S. and Webb, A. (2003) 'Your friends don't understand': Invisibility and unmet need in the lives of 'young carers', Child and Family Social Work, 8(1): 35-46.

Warren, J. (2005) Carers: 'How the lives of young carers differ from those of young non-carers and how their efforts sometimes go unsupported', Research Matters, 19: 5-10.

Warren, J. (2007) 'Young carers: Conventional or exaggerated levels of involvement in domestic and caregiving tasks?' Children and Society, 21(2): 136-46.

Warren, J. (2008) 'Young carers: still 'hidden' after all these years?' Research, Policy and Planning, 26(1): 45-56.

Waters, S. and Rigby, A. (2008) The Lulus model: A peer support pilot program for young people, Victoria, Australia: Carers Association Victoria.

Wayman, S., Raws, P. and Leadbitter, H. (2016) There's nobody is there - no one who can actually help?' The challenges of estimating the number of young carers and knowing how to meet their needs, London: The Children's Society.

Yeandle S.M. and Buckner L.J. (2007) Carers, Employment and Services: time for a new social contract?, Carers UK.

1. 'The LSYPE was a panel study of young people which began in 2004 , with over 15,000 young people aged 13 and 14 completing questionnaires, and finished in 2010 with over 9000 young people in the original cohort still completing questionnaires (Hounsell, 2013: 5).

\section{Acknowledgements}

We are very grateful to Dr Katrina Lloyd who commented on earlier drafts of this paper. Her insights and advice were invaluable. 